\title{
ВЛИЯНИЕ СТРЕССА НА ПРОЦЕСС ПРИНЯТИЯ РЕШЕНИЙ
}

\section{IMPACT OF STRESS ON DECISION MAKING}

\section{E. Matveeva}

Summary: A key problem that animals have faced throughout evolution is finding food (for example, when to abandon the current food source in search of a better one). In such foraging decisions, the quality of the environment as a whole can be used to assess the value of future unknowns against which current prospects are compared. Many decisions that people make are reminiscent of the problem of finding food, where a currently known option has to be compared with an unfamiliar alternative. Indeed, intuitively, what might seem like a good option (eg a job offer) versus potential future options depends on the overall quality of the environment (in a particular situation, the labor market).

This article discusses the hypothesis that such decisions, like foraging, are inherently sensitive to stress, a physiological response that tracks biologically significant changes in the context of the environment. A number of studies confirm that stress tempts decision-makers to overexploit current opportunities over optimal choices. This overexploitation can be an adaptive response to situations that threaten homeostasis. Strengthening exploitative behavior is appropriate when there is a lower overall environmental quality score.

Stress activates biological systems that monitor and respond to changes in the environment, organizing a series of hormonal, neurophysiological and behavioral adjustments for this. To the extent that stress signals negative information about the environment, it should accordingly be associated with lower perceived average reward rates and greater exploitation of current opportunities.

The key role of stress in assessing environmental quality is consistent with its broader role in providing a coordinated body response to complex contexts. It is intuitively obvious that stress contributes to a more negative assessment of the environment, and a stressful environment is almost necessarily defined as repulsive and threatening. However, when the circumstances of the stressor and the circumstances of the decision problem do not match, over-exploitative and pessimistic biases can become maladaptive or pathological.

Keywords: stress, decision making, environment, exploration, exploitation, choice, reward.
Матвеева Евгения Юрьевна

Аспирант, Новосибирский государственный университет экономики и управления, г. Новосибирск epoteruha@mail.ru

Аннотация: Ключевая проблема, с которой животные сталкивались на протяжении всей эволюции, заключается добывании пищи (например, когда стоит отказаться от текущего источника пищи в поисках лучшего). В таких решениях о добыче пищи качество окружающей среды в целом может использоваться для оценки ценности будущих неизвестных вариантов, с которыми сравниваются текущие перспективы. Многие решения, которые принимают люди, напоминают проблемы поиска пищи, где известный в настоящее время вариант должен быть сопоставлен с незнакомой альтернативой. Действительно, интуитивно то, что могло бы показаться хорошим вариантом (например, предложение работы), по сравнению с потенциальными будущими вариантами, зависит от общего качества среды (в конкретной ситуации, рынка труда).

В данной статье рассматривается гипотеза, что такие решения, подобные поиску пищи, характерно чувствительны к стрессу, физиологической реакции, которая отслеживает биологически значимые изменения в контексте окружающей среды. Ряд исследований подтверждает, что стресс склоняет людей, принимающих решения, к чрезмерному использованию текущих возможностей по сравнению с оптимальным выбором. Такая чрезмерная эксплуатация может быть адаптивной реакцией на ситуации, которые представляют угрозу для гомеостаза. Усиление эксплуататорского поведения уместно, когда имеется более низкая оценка общего качества окружающей среды.

Стресс задействует биологические системы, которые отслеживают и реагируют на изменения в окружающей среде, организуя для этого ряд гормональных, нейрофизиологических и поведенческих корректировок. В той степени, в которой стресс сигнализирует о негативной информации 06 окружающей среде, он, соответственно, должен быть связан с более низкой воспринимаемой средней скоростью вознаграждения и с большей эксплуатацией текущих возможностей.

Ключевая роль стресса в оценке качества окружающей среды согласуется с его более общей ролью в обеспечении скоординированной реакции организма на сложный контекст. Интуитивно очевидно, что стресс способствует более негативной оценке окружающей среды, а стрессовая среда почти обязательно определяется как отталкивающая и угрожающая. Однако, когда обстоятельства фактора стресса и обстоятельства проблемы принятия решения не совпадают, чрезмерно эксплуататорские и пессимистические предубеждения могут стать дезадаптивными или патологическими.

Ключевые слова: стресс, принятие решений, окружающая среда, исследование, эксплуатация, выбор, вознаграждение.

являются примерами проблемы исследования/эксплуатации. Исследование - это выбор варианта, о котором известно меньше, в то время как эксплуатация - это принятие всего ранее изученного. Принятие решений в таких ситуациях зависит от прошлого опыта, формирующего ожидания относительно типа, а также вероятности вознаграждений и наказаний. Таким образом, если полагать, что мир всегда был жесток и несправедлив, то 
создается ожидание того, что любой сделанный выбор приведет к нежелательному результату. Следуя этой логике, человек может с большей долей вероятности воспользоваться знакомым, но неоптимальным вариантом, чем исследовать альтернативный путь. В свою очередь стресс является одним из факторов, который приводит к восприятию окружающей среды как враждебной, и поэтому способствует выбору в пользу всего изведанного, а не исследованию.

Системный анализ влияние стресса на модель принятия решения был проведен Дженнифер Леноу совместно с другими американскими исследователями с использованием задачи виртуального сбора урожая. Согласно условиям эксперимента, участники проводили время в каждом из четырех садов с целью собрать как можно больше яблок. Во всех испытаниях была заложена возможность остаться на месте или перейти к другому дереву, но при этом каждый последующий урожай с одного и того же дерева приводил к появлению немного меньшего количества яблок, поэтому в какой-то момент было бы разумно перейти к следующему дереву. В цветущих садах, которые позиционировали благоприятную среду, время в пути до следующего дерева было коротким, а в суровых условиях виртуальной окружающей среды данный показатель был больше. Представители экспериментальной группы полностью погрузили руку в холодную воду, чтобы вызвать острый стресс перед выполнением задания, тогда как контрольная группа погрузила руку в теплую воду. Реакция кортизола на фактор стресса использовалась как непрерывный показатель острого стресса. Участники также сообщили о своем восприятии хронического стресса.

Склонность к исследованию/использованию была оценена с точки зрения порога выхода к последующему дереву. Как и ожидалось, участники имели более высокие пороги выхода в живописных садах, что подтверждает использование качества окружающей среды для принятия решений. Вне зависимости от условий испытуемые с более высоким уровнем кортизола показали более низкие пороги выхода, чем участники с меньшим стрессом. Для дальнейшей интерпретации результатов пороговые значения выхода сравнивались с оптимальным порогом выхода, которые могли бы максимизировать вознаграждение. Отклонения от этого оптимального значения были рассчитаны для каждого субъекта и описаны с точки зрения недостаточного использования и чрезмерной эксплуатации. И острый, и хронический стресс были связаны с чрезмерной эксплуатацией.

Основываясь на полученных результатах, американские исследователи предполагают, что стресс приводит к чрезмерной эксплуатации в принятии решений из-за предвзятого восприятия качества окружающей среды, иными словами люди, находящиеся в стрессовом состоянии, воспринимают окружающую среду как более суровую и враждебную, чем она есть на самом деле. Однако, теоретически существуют и другие механизмы, влияющие на поведение при принятии решений. Так, например, стресс склоняет людей к бездействию, а не побуждает к активности. Серия исследований, проведенных командой немецких ученых, показала, что стресс препятствует активности независимо от того, нужно ли участникам действовать, чтобы получить награду или избежать наказания. Второй вывод, к которому пришли авторы, заключается в том, что стресс смещает внимание и когнитивный фокус от будущего к настоящему времени. Предвзятость, ориентированная на настоящее, может уменьшить объем исследований во время поиска решения.

Возвращаясь к ранее озвученному эксперименту, где перемещение между садами и деревьями представляет собой действие, общая склонность к бездействию объясняет тенденцию стрессированных участников оставаться на одном участке, а не переходить на новый.

Другой потенциальный механизм, с помощью которого стресс может влиять на поведение исследования/ использования, - это снижение когнитивной гибкости, чему способствует префронтальная кора. Полноценное исследование требует когнитивной гибкости, это связано с необходимостью обновлять представления об окружающей среде. Напротив, оставаться на одном месте дольше, чем это оптимально, может быть формой персеверации, связанной со стрессом. Безусловно, префронтальная кора очень чувствительна к стрессу. Острый стресс приводит к высвобождению глюкокортикоидов, которые, в свою очередь, снижают функцию префронтальной коры. Хронический стресс также связан со снижением префронтальной функции, поскольку стабильно высокие уровни глюкокортикоидов вызывают ретракцию дендритов. В то же время хронические стрессоры усиливают контроль миндалевидного тела над префронтальной корой, облегчая ориентированность на привычки и персеверацию. Таким образом, как острые, так и хронические стрессоры приводят к нарушению префронтальной функции и увеличению зависимости от лимбических структур для принятия решений. Эта измененная функция мозга снижает когнитивную гибкость и увеличивает настойчивость, что может привести к более высокому уровню эксплуатации при принятии решения.

Результаты эксперимента американских ученых совпадают с выводами исследований, в которых изучалось влияние стресса в раннем возрасте на тактику эксплуатации при принятии решений. Авторы сравнили подростков, которые были помещены в детские учреждения в младенчестве, с подростками, воспитанными в домаш- 
ней обстановке, во время выполнения задания с вознаграждением. Задание заключалось в том, что каждый запуск воздушного шара мог привести либо к накоплению большего количества очков, либо к потере всех баллов. Подростки, которые выросли вне семьи, «обналичивали» свои заработки раньше, чем группа сравнения, что отражает тенденцию использовать безопасный вариант, а не исследовать возможность получения большего количества баллов. Кроме того, разлука с матерью в младенчестве была связано с меньшими физическими возможностями у испытуемых подростков. Эти результаты коррелируют с представлением о том, что воздействие стресса снижает объем исследования/изучения ситуации.

Представление о том, что стресс мешает организму исследовать различные варианты, имеет важное значение для процессов обучения на протяжении всей жизни. Частично обучение происходит за счет выборки информации из своего окружения: в ситуациях, когда вероятность различных результатов неизвестна, необходимо исследовать различные варианты ассоциаций действие-результат. Если новая информация набирается с меньшей частотой из-за стресса, обучение может ухудшиться. Действительно, недавние исследования показывают снижение способности ассоциативного обучения у подростков, которые подвергались стрессу в раннем детстве.

Наибольшую актуальность получило исследование влияния стресса на мотивированное поведение, в частности потенциальные взаимосвязи между исследованием/эксплуатацией и получением вознаграждения, а также их нейронными субстратами. Эти процессы зависят от перекрывающихся цепей мозга, включая полосатое тело и префронтальную кору. Воздействие стресса глубоко влияет на структуру и взаимосвязь префронтальных и полосатых областей, а тяжелый стресс в раннем периоде жизни связан со снижением ответной реакции полосатого тела на вознаграждение. Более того, как полосатое тело, так и префронтальная кора являются компонентами дофаминергических путей вознаграждения. На сегодняшний день уже имеются данные о том, что стрессовое воздействие изменяет функцию дофамина, хотя воздействие стресса на дофаминовые системы оказывается сложным и может варьироваться в зависимости от типа стрессора. Для более полного анализа необходимы дополнительные исследования в части более систематического изучения того, как различные типы стрессоров влияют на дофаминовые системы и как дофамин, в свою очередь, регулирует исследование и эксплуатацию. Это направление исследований может помочь в лечении расстройств, при которых могут быть нарушены дофаминовые системы, таких как депрессия.

Несмотря на негативные аспекты стресса, физические и поведенческие реакции на стрессоры эволюционировали, чтобы способствовать выживанию организма. Стресс зачастую ассоциируется с суровыми условиями, в которых исследование вряд ли будет связано с вознаграждением. Неадаптивные последствия стресса возникают, когда существует несоответствие между реакцией на стресс и текущей средой (например, человек ведет себя так, как будто он находится в суровых условиях, когда он находится в благополучной среде).

Важно отметить, что стресс может искажать восприятие качества окружающей среды через механизмы когнитивной оценки. Негативные аффективные состояния, такие как грусть или страх, имеют эффект переноса на оценку, приводя к более негативным суждениям в эмоционально нерелевантных областях. Как острые, так и продолжительные состояния негативного аффекта могут приводить к когнитивным и поведенческим искажениям, которые неоптимальны или дезадаптивны в несоответствующих контекстах. Например, более негативная оценка качества своего окружения (в данном случае, рынка труда) может побудить к использованию неоптимальных вариантов (остаться на рабочем месте с уменьшением отдачи от вложений времени и энергии), а не поиск альтернативы. Неоптимальные модели поведения становится все труднее преодолевать, потому что они усиливают негативные представления об окружающей среде, подчеркивая тесную взаимную связь между выбранными действиями, и информацией, о среде. Люди с повышенным риском ежедневного стресса (с тяжелым финансовым положением, тревожные или дискриминируемые) и люди, которые испытывают патологические стрессовые состояния, особенно уязвимы для этих эффектов.

Если вспомнить исследование, о котором шла речь в самом начале, и стресс от погружения руки в холодную воду, и хронический стресс повседневной жизни повлияли на принятие решений во время несвязанной задачи по добыче пищи, что привело к отказу от исследования и снижению производительности. Более того, последствия стресса в раннем детстве сохраняются на протяжении всей жизни, потенциально приводя к изменениям в механизме принятии решений, которые препятствуют обучению. Таким образом, стресс оказывает глубокое влияние на принятие решений, но необходимо учитывать также, как определенные типы и продолжительность стресса влияют на различные аспекты мотивированного поведения, такие как оценка вознаграждения, представления целей и ожидания в отношении будущего. 


\section{ЛИТЕРАТУРА}

1. Абабков В.А., Перре М. Адаптация к стрессу. - СПб.: «Речь», 2010.- 169 с.

2. Бодров В.А. Психологический стресс: развитие и преодоление. М.: Пер Сэ, 2006.- 25 с.

3. Брайт, Джонс - Стресс. Мифы, теории, исследования. - СПб.: ПРАЙМ-ЕВРОЗНАК, 2003. - 214-219 с.

4. Гринберг Дж. Управление стрессом. - СПб.: Питер, 2011. С. 128-133.

5. Дикая Л.Г. Психическая саморегуляция функционального состояния человека (системно-деятельностный подход). М.: Изд-во «Институт психологии PAH», 2003.- 52c.

6. Селье Г. Стресс без дистресса. - М.: «Прогресс», 2009. - 123-139 с.

7. Cohen S, Kamarck T., Mermelstein R. (1983) A global measure of perceived stress. J Health Soc Behav 24:385-396p.

8. Constantino S.M., Daw N.D. (2015) Learning the opportunity cost of time in a patch-foraging task. Cogn Affect Behav Neurosci 15:837-853p.

9. Daw N.D., O'Doherty J.P., Dayan P., Seymour B., Dolan R.J. (2006) Cortical substrates for exploratory decisions in humans. Nature 44:876-879 p.

10. Dias-Ferreira E., Sousa J.C., Melo I., Morgado P., Mesquita A.R., Cerqueira J.J., Costa RM., Sousa N. (2009) Chronic stress causes frontostriatal reorganization and affects decision-making. Science 325:621-625 p.

11. Frankenhuis W.E., Panchanathan K., Nettle D (2016) Cognition in harsh and unpredictable environments. Curr Opin Psychol 7:76-80 p.

12. Hanson J.L., van den Bos W., Roeber B.J., Rudolph K.D., Davidson RJ., Pollak S.D. (2017) Early adversity and learning: implications for typical and atypical behavioral development. J Child Psychol Psychiatry 58:770-778 p.

13. Lenow J.K., Constantino S.M., Daw N.D., Phelps E.A. (2017) Chronic and acute stress promote overexploitation in serial decision making. J. Neurosci 37:56-58 p.

$$
\text { ○ Матвеева Евгения Юрьевна (epoteruha@mail.ru). }
$$

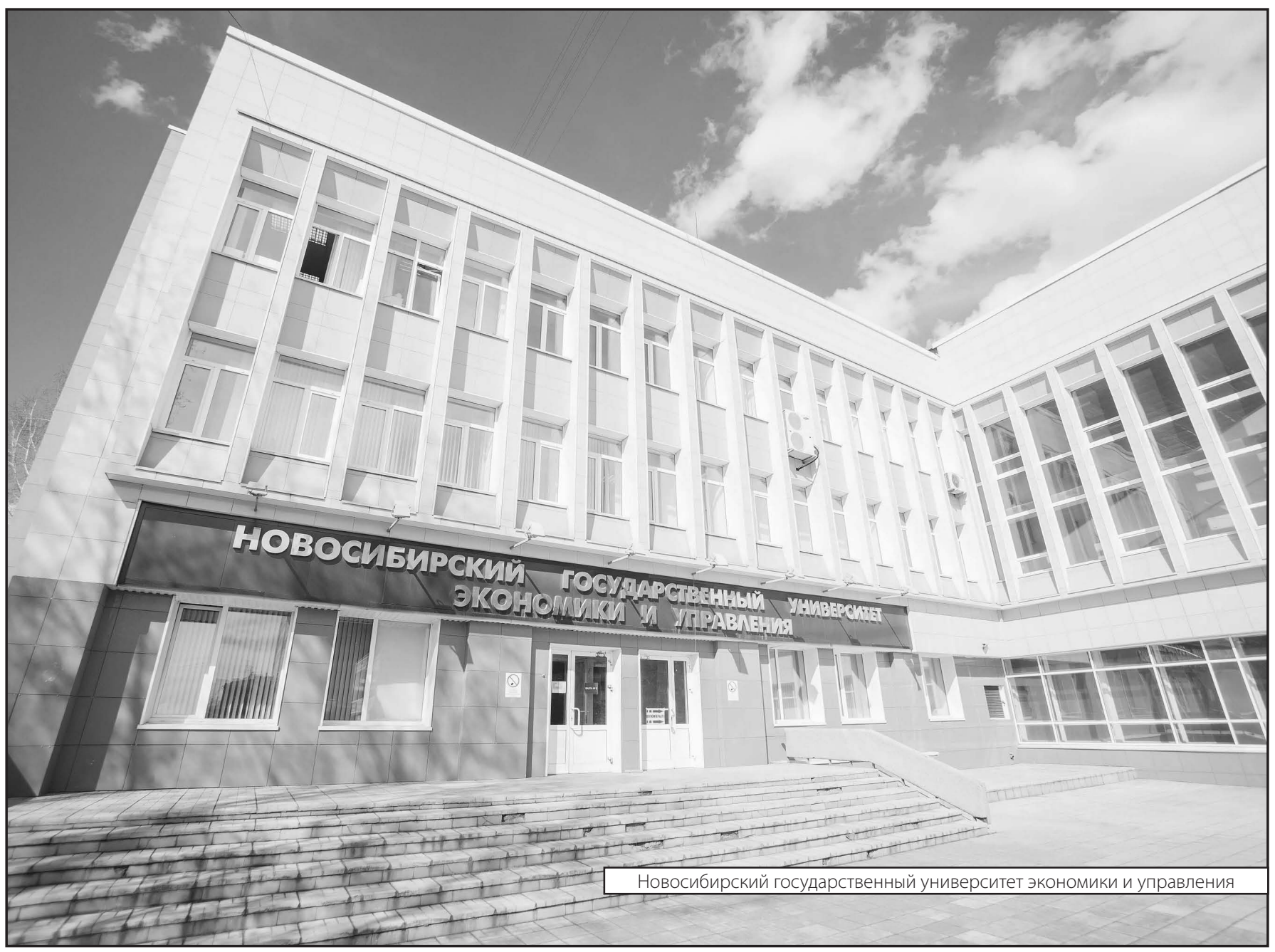

